\title{
A Randomized Clinical Trial of Levonorgestrel Intrauterine System with or without Metformin for Treatment of Endometrial Hyperplasia without Atypia in Indian Women
}

\author{
Ramya Dinnekere Ravi ${ }^{1}$, Jasvinder Kalra ${ }^{1 *}$, Radhika Srinivasan ${ }^{2}$, Rashmi \\ Bagga $^{1}$, Vanita Jain ${ }^{1}$, Vanita Suri ${ }^{1}$, Naresh Sachdeva ${ }^{3}$
}

\begin{abstract}
Background: Endometrial cancer is the second most frequent genital malignancy in women, which is showing a constant rise all over world. Endometrial hyperplasia is the precursor of endometrial cancer. Levonorgestrel intrauterine system is the first line management in patients with endometrial hyperplasia without atypia. Metformin has shown to reverse endometrial hyperplasia, but its effectiveness and safety in endometrial hyperplasia is uncertain. Objective: To compare the efficacy in terms of histopathological response, clinical response and safety at the end of 6 months in patients with endometrial hyperplasia without atypia managed with levonorgestrel intrauterine system alone versus patients managed with levonorgestrel intrauterine system plus metformin. Methods: The randomized control trial was conducted on 51 cases of endometrial hyperplasia without atypia. Twenty-five subjects were prescribed metformin 500mg twice daily with levonorgestrel intrauterine system and 26 subjects, with levonorgestrel intrauterine system only for 6 months. At the end of 6 months, endometrial sampling was performed for histopathological response. Results: Clinical response was observed in 23 of 25 subjects in metformin group and 22 of 24 in levonorgestrel only group. The metformin group responded significantly with amenorrhea $(p=0.0053)$, while levonorgestrel only group responded with regular cycles $(\mathrm{p}=0.027)$. At the end of study, of 46 subjects available for histopathological evaluation, $100 \%$ subjects in metformin group and $95.45 \%$ in levonorgestrel only group $(\mathrm{p}=0.47826)$ showed complete response. The metformin group had a significant reduction in body mass index at end of study $[\mathrm{P}=0 \cdot 023,95 \%$ confidence interval $(-1.7802,-0.1418)]$. Conclusion: No significant difference in regression of endometrial hyperplasia was observed on adjunctive use of metformin but a significant reduction in BMI was observed. Use of metformin in obese patients may improve the treatment response.
\end{abstract}

Keywords: Endometrial hyperplasia- metformin- levonorgestrel- LNG-IUS- endometrial hyperplasia without atypia

Asian Pac J Cancer Prev, 22 (3), 983-989

\section{Introduction}

Endometrial Hyperplasia (EH) refers to a spectrum of morphological and biological alterations of endometrial glands and stroma, with exaggerated physiological state at one end of the spectrum and carcinoma in-situ on the other end. The most common presentation of $\mathrm{EH}$ is Abnormal Uterine Bleeding (AUB), usually sufficient to interfere with the quality of life. The World Health Organization (WHO) 2014 classification for $\mathrm{EH}$ has divided EH into EH without atypia and EH with atypia (Carcangiu et al., 2014). EH without atypia is a benign change with no underlying genetic alterations and it reverts back to normal after the endocrine milieu has normalized. It is clinically important as the risk of progression to Endometrial Cancer (EC) is $1-3 \%$ (Kurman et al., 1985). The key goal of management of $\mathrm{EH}$ is reversion to normal endometrium and prevention of development of carcinoma. The available management options include observation only with follow up or medical management like progestins, gonadotropin-releasing hormone analogues, metformin, ovulation induction and surgery (Chandra et al., 2016).

Management of EH has evolved over years. Simple EH without atypia was initially treated with surveillance only. Following the demonstration of risk of progression to cancer, newer modalities of treatment were introduced. The management evolved from cyclical to continuous oral progestins and currently the first line of management

${ }^{1}$ Department of Obstetrics \& Gynaecology, Post Graduate Institute of Medical Education and Research, Chandigarh, India. ${ }^{2}$ Department of Cytology \& Gynecological Pathology, Post Graduate Institute of Medical Education and Research, Chandigarh, India. ${ }^{3}$ Department of Endocrinology, Post Graduate Institute of Medical Education and Research, Chandigarh, India. *For Correspondence:drjasvinpgi3@gmail.com 
is Levonorgestrel intrauterine system (LNG-IUS) as recommended by Royal College of Obstetricians and Gynaecologists (RCOG) (Royal College of Obstetricians and Gynaecologists [RCOG], 2016).

Insulin resistance is a well-studied aetiopathological feature associated with $\mathrm{EH}$, which can be targeted for the management (Kaya et al., 2019). Metformin is used widely in management of insulin resistance and it's anti-proliferative, anti-invasive, anti-metastatic and anti-estrogenic effect on the endometrium makes it a logical treatment option (Tan et al., 2011; Cantrell et al., 2010). The property of metformin to induce progesterone receptors in endometrium may also help to overcome the progestin resistance (Xie et al., 2011). Various in vitro studies have shown that metformin causes cell cycle arrest and inhibits oestrogen dependent proliferation (Zhang et al., 2009). In recent years following the case report of use of metformin to treat EH (Session et al., 2003), various trials have come up with metformin as a management option for EH. Recent studies by Sharifzadeh et al. and Tabrizi et al. have shown that metformin can be used as an effective alternate management option for treatment of EH (Sharifzadeh et al., 2017; Tabrizi et al., 2014).

There was a need to study the effect of adding metformin to the standard treatment of $\mathrm{EH}$ without atypia in a prospective randomized trial. The current study intends to compare the efficacy of LNG-IUS plus metformin versus LNG-IUS alone in terms of histopathological response, clinical response and the adverse effects in patients with EH without atypia.

\section{Materials and Methods}

This is a randomized prospective interventional study conducted in the Department of Obstetrics and Gynaecology and the Department of Pathology, Post Graduate Institute of Medical Education and Research, Chandigarh, India, from July 2016 to June 2018. Approval from the institutional ethics committee was obtained and the details have been uploaded in the clinical trial registry of India (CTRI/2017/05/008548).

Patients who presented with AUB and had a histopathological diagnosis of EH without atypia (Carcangiu et al., 2014) after Endometrial Biopsy (EB) were approached. Patients who understood the study design and were able to comply with the EB at specified interval were included in the study after obtaining an informed written consent. Patients who were 1) on progestin therapy for more than 15 days, 2) with uterine or extra uterine malignancy 3) with renal dysfunction, liver disease or diabetes mellitus 4)with history of hypersensitivity to metformin or discontinuation due to adverse effects 5) pregnancy or lactation, 6) recent $(<4$ weeks) or active documented Pelvic Inflammatory Disease (PID) or cervical infection 7) with immune-suppression 8) abnormal Pap smear 9) contraindication to metformin or progestin or IUS were excluded from the study.

\section{Methodology}

Complete medical history, findings of general physical examination, systemic and gynaecological examination were recorded on a pre-designed proforma. Body Mass Index (BMI) of the patients was calculated. Patient's haematological and biochemical parameters such as hemogram, coagulogram, fasting and postprandial blood sugars, fasting insulin level, thyroid profile, renal function test, liver function test and lipid profile were noted for any abnormalities. Insulin resistance using fasting blood sugar and fasting insulin level was calculated using the HOMA model [HOMA1-IR = (fasting plasma insulin * fasting plasma glucose)/22.5] (Matthews et al., 1985). Fifty-one recruited patients were randomized by asking them to pick up an envelope from a set of similar looking pre-sealed opaque envelopes prepared by a third party into LNG-IUS with metformin group (Group M) and LNG-IUS alone group (Group L). Patients in both the groups underwent LNG-IUS (MIRENA, manufactured by Bayer Oy, Finland and imported and marketed by Bayer Zydus Pharma Pvt. Ltd. which contains $52 \mathrm{mg}$ Levonorgestrel with a release rate of approximately $20 \mu \mathrm{g}$ per day) insertion under aseptic precautions. The patients in group $\mathrm{M}$ were prescribed tablet metformin 500mg once a day for 1 week followed by twice a day for the rest of the duration of the study in addition to LNG-IUS. A pictorial menstrual diary was provided to all the patients to document the menstrual bleeding patterns for 6 months.

Treatment response was assessed by repeat EB after six months of treatment. During the response assessment by histopathological examination, the pathologists were unaware of the management that the patient had received. Lipid profile, insulin resistance, hemogram, coagulogram, liver and renal function tests and BMI were reassessed to evaluate and compare the adverse effects among the groups.

The primary outcome was response to treatment compared between the groups as complete response, no response and progressive disease. A complete response was defined as reversion of EH to proliferative or secretory endometrium, no response as the persistence of $\mathrm{EH}$, and progressive disease as the appearance of atypia or EC. In secondary outcome, the comparison was made between the two groups regarding regression of menstrual symptoms (clinical response), effect on BMI and other biochemical parameters, need for the requirement of additional oral progesterone, adverse effects and patients opting for hysterectomy during the treatment period.

The distribution of the variables was tested with the Shapiro-Wilk test/Kolmogorov-Smirnov tests of normality. Group comparisons of values of skewed data were made with the Mann Whitney test for the two groups. Independent t-test was applied for comparison of the two groups when data was normally distributed. Group comparisons were made with the Chi-Square test or Fisher's exact test. Change was calculated for the variables to see change by the formula (post - pre). A P value $<0 \cdot 05$ was considered significant. Analysis was conducted using IBM SPSS STATISTICS (version 22.0).

\section{Results}

During the recruitment period, 177 patients were diagnosed with EH without atypia on EB. Among which 
126 patients were excluded as they did not fulfil the inclusion and exclusion criteria. Among 51 patients enrolled in the study, 25 patients were randomized to group $\mathrm{M}$ and 26 to group L (Figure 1). At the end of 6 months, 46 patients were available for histopathological evaluation and 49 patients were available to evaluate the clinical response. Table 1 lists the general information of the study participants. The mean age of the patients was 44 years and the average parity being two. None of the 51 patients were under weight $\left(<18.5 \mathrm{~kg} / \mathrm{m}^{2}\right), 72 \%$ of patients in group $M$ and $69 \%$ in group L were obese $\left(\geq 25 \mathrm{~kg} / \mathrm{m}^{2}\right)$ (Misra et al., 2009). The pattern of AUB on presentation is depicted in table 1 . The patients were distributed equally in both the groups for presenting complaints and general features.

The base line investigations were comparable in both the groups, except for triglycerides $(\mathrm{P}=0 \cdot 019)$ which was significantly higher in group L. Both the groups were matched for fasting plasma insulin and HOMA- IR as well.

There was negative correlation between BMI and endometrial thickness (ET) in the recruited patients $(\mathrm{n}=51)$, but it was not clinically significant (Pearson correlation $=-0.085)(\mathrm{P}=0.553)$. But a significant negative correlation between HOMA-IR levels and ET, (Pearson correlation $=-0 \cdot 297)(\mathrm{P}=0 \cdot 034)$ was observed.

\section{Comparison of treatment response between the groups}

Of the 46 patients who were available for histopathological evaluation after 6 months, 24 of 25 were from group $\mathrm{M}$ and 22 of 26 were from group L as depicted in table 2. One patient each from both the groups were not available for post treatment EB. Of the remaining three patients of group $\mathrm{L}$, one patient expelled LNG-IUS in 2 weeks, one patient refused EB at the end of 6 months and one patient underwent hysterectomy in a different centre within 2 months due to persistent bleeding. In group M 100\% (24/24) patients showed a complete

Table 1. Demographic Characteristics of the Study Subjects, Pattern of AUB at Presentation and Pre-Treatment baseline Investigations of the Subjects

\begin{tabular}{|c|c|c|c|c|}
\hline Parameter & $\begin{array}{c}\text { Group M } \\
n=25\end{array}$ & $\begin{array}{c}\text { Group L } \\
n=26\end{array}$ & $\begin{array}{c}\text { Total } \\
(\mathrm{n}=51)\end{array}$ & $\mathrm{P}$-value \\
\hline \multicolumn{5}{|l|}{ Variable } \\
\hline \multicolumn{5}{|l|}{$($ Mean $\pm \mathrm{Sd})$} \\
\hline Age (years) & $44 \cdot 2 \pm 5 \cdot 82$ & $44 \cdot 73 \pm 5 \cdot 96$ & $44 \cdot 47 \pm 5 \cdot 839$ & $0 \cdot 749$ \\
\hline Parity & $2 \cdot 24 \pm 0 \cdot 93$ & $2 \cdot 27 \pm 0 \cdot 87$ & $2 \cdot 25 \pm 0 \cdot 89$ & 0.909 \\
\hline Age at menarche (years) & $13 \cdot 84 \pm 1 \cdot 57$ & $14 \cdot 12 \pm 1 \cdot 45$ & $13 \cdot 98 \pm 1 \cdot 50$ & $0 \cdot 519$ \\
\hline BMI $\left(\mathrm{kg} / \mathrm{m}^{2}\right)$ & $29 \cdot 75 \pm 6 \cdot 85$ & $26 \cdot 74 \pm 3 \cdot 70$ & $28 \cdot 22 \pm 5 \cdot 63$ & $0 \cdot 060$ \\
\hline \multicolumn{5}{|l|}{ Complaint, n (\%) } \\
\hline HMB & $01(4 \cdot 0 \%)$ & $05(19 \cdot 2 \%)$ & $06(11 \cdot 8 \%)$ & \\
\hline IrregMB & $07(28 \%)$ & $11(42 \cdot 3 \%)$ & $18(35 \cdot 3 \%)$ & \\
\hline HPMB & $14(56 \%)$ & $09(34 \cdot 6 \%)$ & $23(45 \cdot 1 \%)$ & $0 \cdot 131$ \\
\hline PMB & $03(12 \%)$ & $01(3 \cdot 8 \%)$ & $04(07 \cdot 8 \%)$ & \\
\hline \multicolumn{5}{|l|}{ Investigation (Mean $\pm \mathrm{SD})$} \\
\hline HAEMOGLOBIN (g/dL) & $11 \cdot 20 \pm 1 \cdot 42$ & $11 \cdot 12 \pm 1 \cdot 44$ & & $0 \cdot 833$ \\
\hline T. BILIRUBIN(mg/dL) & $0 \cdot 61 \pm 0 \cdot 21$ & $0 \cdot 58 \pm 0 \cdot 25$ & & $0 \cdot 679$ \\
\hline AST (U/L) & $27 \cdot 88 \pm 8.53$ & $26 \cdot 26 \pm 10 \cdot 55$ & & $0 \cdot 551$ \\
\hline ALT (U/L) & $29 \cdot 27 \pm 11 \cdot 87$ & $27 \cdot 23 \pm 9 \cdot 85$ & & $0 \cdot 508$ \\
\hline ALP (U/L) & $108 \cdot 13 \pm 44 \cdot 90$ & $116 \cdot 68 \pm 43 \cdot 28$ & & $0 \cdot 492$ \\
\hline UREA (mg/dL) & $22 \cdot 10 \pm 5 \cdot 60$ & $23 \cdot 97 \pm 6 \cdot 39$ & & $0 \cdot 269$ \\
\hline CREATININE (mg/dL) & $0 \cdot 69 \pm 0 \cdot 15$ & $0 \cdot 69 \pm 0 \cdot 20$ & & $0 \cdot 967$ \\
\hline $\mathrm{FBS}(\mathrm{mg} / \mathrm{dL})$ & $90 \cdot 35 \pm 10 \cdot 43$ & $90 \cdot 11 \pm 7 \cdot 78$ & & 0.926 \\
\hline PPBS (mg/dL) & $123 \cdot 05 \pm 22 \cdot 45$ & $130 \cdot 19 \pm 24 \cdot 55$ & & $0 \cdot 283$ \\
\hline TRIGLYCERIDE (mg/dL) & $107 \cdot 91 \pm 32 \cdot 69$ & $134 \cdot 97 \pm 45 \cdot 76$ & & $0 \cdot 019$ \\
\hline CHOLESTEROL (mg/dL) & $187 \cdot 74 \pm 33 \cdot 31$ & $190 \cdot 20 \pm 38 \cdot 84$ & & $0 \cdot 081$ \\
\hline $\mathrm{LDL}(\mathrm{mg} / \mathrm{dL})$ & $121 \cdot 96 \pm 36 \cdot 64$ & $114 \cdot 33 \pm 33 \cdot 82$ & & $0 \cdot 444$ \\
\hline HDL (mg/dL) & $46 \cdot 19 \pm 8 \cdot 71$ & $49 \cdot 17 \pm 11 \cdot 49$ & & $0 \cdot 302$ \\
\hline FPI $(\mu \mathrm{U} / \mathrm{ml})$ & $11 \cdot 65 \pm 5 \cdot 85$ & $9 \cdot 73 \pm 4 \cdot 86$ & & $0 \cdot 210$ \\
\hline HOMA- I R (mg/dL) & $2 \cdot 66 \pm 1 \cdot 52$ & $2 \cdot 15 \pm 1 \cdot 08$ & & $0 \cdot 171$ \\
\hline $\mathrm{ET}(\mathrm{mm})$ & $13 \cdot 44 \pm 5 \cdot 51$ & $13 \cdot 90 \pm 5 \cdot 18$ & & $0 \cdot 760$ \\
\hline
\end{tabular}

BMI, Body mass index; HMB, Heavy menstrual bleeding; IrregMB, Irregular menstrual bleeding; HPMB, heavy prolonged menstrual bleeding; PMB, postmenopausal bleeding; AST, aspartate transaminase; ALT, Alanine transaminase; ALP, alkaline phosphatase; FBS, fasting blood sugar; PPBS, postprandial blood sugar; LDL, low density lipoprotein; HDL, high density lipoprotein; FPI, fasting plasma insulin; ET, endometrial thickness. 
histopathological response. In group L 95.45\% (21/22) patients showed complete response. One patient of group L who did not have a complete response as per outcome assessment had disordered proliferative endometrium on histopathology and was placed in no response category. No patient showed histological evidence of progression of disease. There was no statistically significant $(\mathrm{P}=$ 0.47826 ) difference in primary outcome between the groups.

As elaborated in Table 2, 49 of 51 patients were available for assessment of clinical response through menstrual diary, including those contacted telephonically. Among 49 patients 45 responded clinically with either amenorrhea, regular cycles or spotting. Clinical response was observed in $92 \%(23 / 25)$ patients in group $\mathrm{M}$ and $91.67 \%(22 / 24)$ of patients in group L. Among patients who failed to respond, one patient of group $\mathrm{M}$ was diagnosed with endometrial polyp at the end of 6 months and underwent hysteroscopic polypectomy which on histopathology was a benign adenomyomatous polyp. There was a significant difference in type of response between the groups at the end of 6 months. Patients on metformin developed amenorrhea $(\mathrm{P}=0.0053)$ more frequently while patients in group $\mathrm{L}$ developed regular cycles $(\mathrm{P}=0.027)$. The mean time of onset of clinical response (reduction in amount of bleeding in subjects with heavy menstrual cycles, and regularization of cycles in subjects with irregular bleeding) in group $M$ was $1 \cdot 79 \pm$ 0.93 months and in group L was $2.00 \pm 1.38$ months, which was not statistically significant $(\mathrm{P}=0.935)$.

A total six subjects required additional oral progestogens for variable duration for symptomatic relief,

Table 2. Histopathological Response to the Treatment, Clinical Response to Treatment, Adverse Effects and Comparison of Change in Parameters after Treatment between the Study Groups

\begin{tabular}{|c|c|c|c|c|c|c|}
\hline \multirow{2}{*}{\multicolumn{2}{|c|}{ Histopathological Response }} & \multirow{2}{*}{$\begin{array}{c}\text { Group M } \\
\mathrm{n}=24^{\mathrm{a}}(\%)\end{array}$} & \multirow{2}{*}{$\begin{array}{c}\text { Group L } \\
\mathrm{n}=22^{\mathrm{a}}(\%)\end{array}$} & \multicolumn{2}{|l|}{ Total } & \multirow[t]{2}{*}{$\mathrm{P}$ value } \\
\hline & & & & $\left(\mathrm{n}=46^{\mathrm{a}}\right)(\%)$ & & \\
\hline \multirow{4}{*}{$\begin{array}{l}\text { Complete } \\
\text { response }\end{array}$} & Pill endometrium & $17(70 \cdot 83 \%)$ & $19(86 \cdot 36 \%)$ & $36(78 \cdot 26 \%)$ & $45(97 \cdot 83 \%)$ & $0 \cdot 47826$ \\
\hline & Late secretory & $03(12 \cdot 50 \%)$ & $02(09 \cdot 09 \%)$ & $05(10 \cdot 87 \%)$ & & \\
\hline & Atrophic & $03(12 \cdot 50 \%)$ & $0(00 \cdot 00 \%)$ & $03(06 \cdot 52 \%)$ & & \\
\hline & Benign polyp & $01(04 \cdot 17 \%)$ & $0(00 \cdot 00 \%)$ & $01(02 \cdot 17 \%)$ & & \\
\hline No response & Disordered proliferative endometrium & $00(00 \cdot 00 \%)$ & $1(04 \cdot 55 \%)$ & $01(02 \cdot 17 \%)$ & $1(02 \cdot 17 \%)$ & \\
\hline \multicolumn{2}{|c|}{ Clinical response } & $\mathrm{n}=25(\%)$ & $\mathrm{n}=24^{\mathrm{b}}(\%)$ & $\mathrm{n}=49^{\mathrm{b}}(\%)$ & & \\
\hline \multicolumn{2}{|l|}{ Amenorrhea } & $15(60 \%)$ & $05(20 \cdot 83 \%)$ & $20(40 \cdot 82 \%)$ & & $0 \cdot 0053$ \\
\hline \multicolumn{2}{|l|}{ Spotting } & $03(12 \%)$ & $05(20 \cdot 83 \%)$ & $08(16 \cdot 33 \%)$ & & $0 \cdot 463$ \\
\hline \multicolumn{2}{|c|}{ Regular cycles } & $05(20 \%)$ & $12(50 \cdot 00 \%)$ & $17(34 \cdot 69 \%)$ & & 0.027 \\
\hline \multicolumn{2}{|l|}{ HMB } & $02(08 \%)$ & $02(08 \cdot 33 \%)$ & $04(08 \cdot 16 \%)$ & & 1 \\
\hline \multicolumn{2}{|c|}{ Adverse effects ${ }^{c}$} & $\mathrm{n}=25(\%)$ & $\mathrm{n}=26(\%)$ & & & \\
\hline \multicolumn{2}{|l|}{ Nausea } & $10(41 \cdot 67 \%)$ & $03(13 \cdot 04 \%)$ & & & $0 \cdot 0265$ \\
\hline \multicolumn{2}{|c|}{ Heaviness in lower abdomen } & $05(20 \cdot 83 \%)$ & $04(17 \cdot 39 \%)$ & & & $0 \cdot 726$ \\
\hline \multicolumn{2}{|c|}{ Pain abdomen } & $05(20 \cdot 83 \%)$ & $06(26 \cdot 09 \%)$ & & & 1 \\
\hline \multicolumn{2}{|c|}{ Investigation } & $\mathrm{n}=24^{\mathrm{a}}($ Mean $\pm \mathrm{SD})$ & \multicolumn{3}{|c|}{$\mathrm{n}=22^{\mathrm{a}}($ Mean $\pm \mathrm{SD})$} & \\
\hline \multicolumn{2}{|c|}{ HAEMOGLOBIN } & $0 \cdot 83 \pm 1 \cdot 31$ & $0 \cdot 86 \pm 1 \cdot 34$ & & & $0 \cdot 948$ \\
\hline \multicolumn{2}{|c|}{$\mathrm{T} \cdot \mathrm{BILIRUBIN}$} & $0 \cdot 14 \pm 0 \cdot 20$ & $0 \cdot 12 \pm 0 \cdot 45$ & & & $0 \cdot 858$ \\
\hline \multicolumn{2}{|l|}{ AST } & $-1 \cdot 72 \pm 7.42$ & $0 \cdot 621 \pm 8 \cdot 69$ & & & $0 \cdot 333$ \\
\hline \multicolumn{2}{|l|}{ ALT } & $-1 \cdot 14 \pm 10 \cdot 27$ & $3 \cdot 11 \pm 11 \cdot 02$ & & & $0 \cdot 185$ \\
\hline \multicolumn{2}{|l|}{ ALP } & $8 \cdot 76 \pm 35 \cdot 54$ & $-4 \cdot 18 \pm 53 \cdot 32$ & & & $0 \cdot 344$ \\
\hline \multicolumn{2}{|l|}{ UREA } & $0 \cdot 71 \pm 6 \cdot 59$ & $0 \cdot 14 \pm 5 \cdot 76$ & & & $0 \cdot 753$ \\
\hline \multicolumn{2}{|c|}{ CREATININE } & $-0 \cdot 04 \pm 0 \cdot 17$ & $0 \cdot 05 \pm 0 \cdot 15$ & & & $0 \cdot 085$ \\
\hline \multicolumn{2}{|l|}{ FBS } & $9 \cdot 30 \pm 18 \cdot 02$ & $6 \cdot 17 \pm 12 \cdot 32$ & & & $0 \cdot 492$ \\
\hline \multicolumn{2}{|l|}{ PPBS } & $20 \cdot 30 \pm 33 \cdot 38$ & $9 \cdot 84 \pm 32 \cdot 18$ & & & $0 \cdot 285$ \\
\hline \multicolumn{2}{|c|}{ TRIGLYCERIDE } & $-1 \cdot 18 \pm 33 \cdot 05$ & $-10 \cdot 12 \pm 38 \cdot 90$ & & & $0 \cdot 408$ \\
\hline \multicolumn{2}{|c|}{ CHOLESTEROL } & $-7 \cdot 27 \pm 27 \cdot 33$ & $-1 \cdot 62 \pm 28 \cdot 52$ & & & $0 \cdot 496$ \\
\hline \multicolumn{2}{|l|}{ LDL } & $-6 \cdot 16 \pm 28 \cdot 38$ & $\begin{array}{c}10 \cdot 67 \pm \\
31 \cdot 89\end{array}$ & & & 0.067 \\
\hline \multicolumn{2}{|l|}{$\mathrm{HDL}$} & $2 \cdot 44 \pm 7 \cdot 47$ & $-1 \cdot 56 \pm 7 \cdot 48$ & & & $0 \cdot 077$ \\
\hline FPI & & $-1 \cdot 06 \pm 5 \cdot 12$ & $-0 \cdot 12 \pm 3 \cdot 14$ & & & $0 \cdot 458$ \\
\hline BMI & & $-0 \cdot 63 \pm 1 \cdot 36$ & $0 \cdot 34 \pm 1 \cdot 39$ & & & 0.023 \\
\hline
\end{tabular}

HMB, Heavy menstrual bleeding; AST, aspartate transaminase; ALT, Alanine transaminase; ALP, alkaline phosphatase; FBS, fasting blood sugar; PPBS, postprandial blood sugar; LDL, low density lipoprotein; HDL, high density lipoprotein; FPI, fasting plasma insulin; BMI, body mass index. ${ }^{\text {a }}$, HPE of EB not available for one subject in group A and four in group B; ${ }^{\text {b }}$, Assessment of clinical response was not available in 2 subjects; ${ }^{c}$, Subjects had more than one complaint (overlap). 


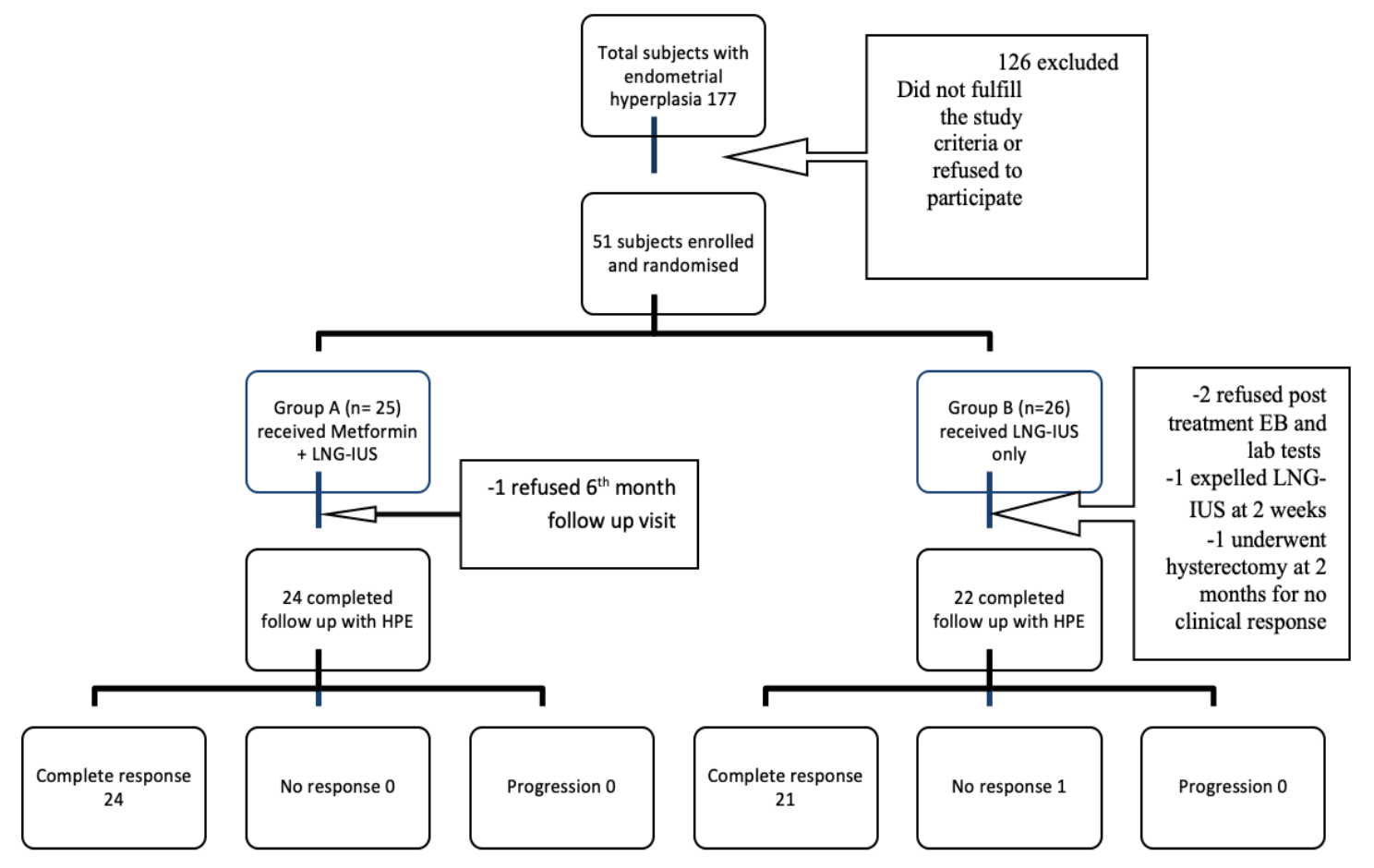

Figure 1. Study Design Flow Chart

one in group $\mathrm{M}$ and five in group $\mathrm{L}$. The mean duration of the requirement was 2 months in group $\mathrm{M}$ and 3·20 $\pm 1 \cdot 304$ months in group L. Two patients of group L underwent hysterectomy during the study period.

The repeat evaluation of biochemical and haematological parameters at the end of the study showed no significant change in baseline parameters. A decrease in mean weight by $1.25 \pm 3.096 \mathrm{~kg}$ was observed in group M patients, whereas group L patients showed an increase of mean weight by $0.818 \pm 3.376 \mathrm{~kg}$, which was statistically significant $(\mathrm{P}=0.0366)$. The difference in change in $\mathrm{BMI}$ between the 2 groups was also significant $[\mathrm{P}=0 \cdot 023,95 \%$ CI (-1.7802,-0.1418)]. There was no significant irreversible adverse effect observed among the subjects during the study period. The observed adverse effects are described in table 2. Following initiation of treatment, subjects in group $\mathrm{M}$ had statistically significant nausea. Nausea settled in both the groups in less than two weeks not requiring the termination of treatment. The heaviness in lower abdomen and pain abdomen was managed with analgesics.

\section{Discussion}

Progesterone is the corner stone in the management of EH without atypia. Studies have shown that addition of metformin can enhance the effect of progesterone and also can be as effective as progesterone therapy on its own. The available published literature so far only includes studies comparing use of oral progestogens with metformin for treatment of EH with and without atypia. However, the present study is first of its kind for use of LNG-IUS with metformin in EH without atypia.

The study has also adopted WHO 2014 classification and introduced the use of pictorial menstrual diary for clinical response assessment. A pilot study by Shan et al., (2014) in 16 patients with EH with atypia showed $75 \%$ cure rate in group treated with Megestrol Acetate (MA) plus metformin compared to $25 \%$ in MA only group during a 3 month follow up. They concluded that metformin plus MA may be a potential alternate therapy for EH with atypia.

In our study, the mean age of subjects, parity and BMI was similar to that observed by Sharifzadeh et al (Sharifzadeh et al., 2017) and Sayyah-melli et al (SayyahMelli et al., 2018). The mean HDL levels in the study were less than $50 \mathrm{mg} / \mathrm{dL}$ suggesting that most of the women met at least one metabolic syndrome criteria. The mean HOMA IR in the study was $2 \cdot 402$ which being greater than 2 suggests insulin resistance for Indian population (Sinha DP et al., 2009). Even though the mean ET (13.68mm) was comparable to other studies (Sayyah-Melli et al., 2018; Korkmaz et al., 2013), our study did not show any significant correlation between ET and BMI in contrast to prior studies. Earlier studies have demonstrated increase in ET with increased BMI (Douchi et al., 1998; Heller et al., 2011). Our study showed a significant negative correlation between HOMA IR and ET, suggesting early onset of hyperplastic changes in endometrium in individuals with insulin resistance. The European studies have suggested a positive correlation between insulin resistance and ET (Navaratnarajah et al., 2008). Hence more studies are required to know the population-based variations.

Even though adding metformin to the first line management (LNG-IUS) showed a better histopathological response, it was not statistically significant as noted in the previous studies (Shan et al., 2014; Korkmaz et al., 2013). Seventy eight percent of the total study subjects had pill endometrium on histopathological response assessment and atrophic endometrium was observed only in group M patients (12.5\%). Tabrizi et al., (2014) observed 87.5\% 
of atrophic endometrium in metformin group and $66.7 \%$ in MA group. Their study did not have pill endometrium as a pathological entity. Pill endometrium is characterized by inactive endometrial glands in decidualized stroma, which is considered as complete response.

The only subject of the study who did not show a complete histological response was the subject with maximum BMI $\left(34.72 \mathrm{~kg} / \mathrm{m}^{2}\right)$ in the group L and with a HOMA IR of $3.5 \mathrm{mg} / \mathrm{dl}$. Women with BMI greater than $34\left(37.72,37.33,49.73,41.38 \mathrm{~kg} / \mathrm{m}^{2}\right)$ showed a complete response in group with metformin. There was also a significant decrease in mean BMI in LNG-IUS plus metformin group. We agree with Korkmaz et al that metformin may be used as an adjunctive therapy for persistent EH in women with high BMI (Korkmaz et al., 2013).

In our study, $22.72 \%$ subjects of group $\mathrm{L}$ required additional oral progesterone compared to only $4.16 \%$ in group $\mathrm{M}$ to control the symptoms in those who had increased bleeding with LNG-IUS initially. Even though not significant, addition of metformin reduced the increased bleeding associated with LNG-IUS.

Evaluation of clinical response using menstrual diary has not been reported in any other study involving treatment of EH with metformin. In the present study, complete amenorrhea was significantly reported in women treated with LNG-IUS plus metformin. El Behery et al observed 26\% amenorrhea in LNG-IUS group compared to none in oral Progestogens group (El Behery et al., 2015).

Only $3.865 \%$ subjects from the study underwent hysterectomy for no relief in symptoms, which was in contrast to that observed by $\mathrm{Abu}$ et al. where rate of hysterectomy was $22 \%$ in individuals treated with LNGIUS (Abu Hashim et al., 2013).

Like other studies, no severe adverse effects were observed in both arms of the study (Shan et al., 2014). Emily $\mathrm{M}$ et al had observed diarrhoea as the most common adverse effect, which was not observed in our study (Emily Meichun Ko et al., 2016).

We observed mean increase in blood sugar levels within both the groups. This finding might have been due to confounding factors like lack of exercise in both the groups, diet, difference in duration of fasting period at the time of blood sampling and also the diet consumed before the postprandial sugar assessment. Estimation of $\mathrm{HbA} 1 \mathrm{c}$ at the time of recruitment of subjects into the study would have overcome this disparity and given a meaningful analysis. The present study was not powered to assess a superiority of adding metformin to LNG-IUS in treatment of EH without atypia as a large sample size is required for any conclusive evidence.

Although the present study did not show significant difference in pathological response on addition of metformin, it showed a significant reduction in BMI, lesser need of oral progesterone to control heavy bleeding following LNG-IUS insertion and better bleeding profile. Further study with a larger sample size, targeting obese population is necessary to reveal the additional benefits and to confirm the findings.

\section{Author Contribution Statement}

The authors confirm contribution to the paper as follows: study conception and design: RDR, JK, RS, RB, NS ; data collection: RDR, JK, RB, VJ, VS ; analysis and interpretation of results: RS, RDR, JK; draft manuscript preparation: RDR and JK. All authors reviewed the results and approved the final version of the manuscript.

\section{References}

Behery MME, Saleh HS, Ibrahiem MA, et al (2015). Levonorgestrel-releasing intrauterine device versus dydrogesterone for management of endometrial hyperplasia Without Atypia. Reprod Sci, 22, 329-4.

Cantrell LA, Zhou C, Mendivil A, et al (2010). Metformin is a potent inhibitor of endometrial cancer cell proliferation--implications for a novel treatment strategy. Gynecol Oncol, 116, 92-8.

Carcangiu ML, Kurman RJ, Carcangiu ML, Herrington CS (2014). WHO Classification of Tumours of Female Reproductive Organs. International Agency for Research on Cancer, Lyon, pp 125-6.

Chandra V, Kim JJ, Benbrook DM, Dwivedi A, Rai R (2016). Therapeutic options for management of endometrial hyperplasia. J Gynecol Oncol, 27, 1-25.

Douchi T, Yoshinaga M, Katanozaka M, Mitani M, Nagata Y (1998). Relationship between body mass index and transvaginal ultrasonographic endometrial thickness in postmenopausal women. Acta Obstet Gynecol Scand, 77, 905-8.

Hashim HA, Zayed A, Ghayaty E, Rakhawy ME (2013). LNGIUS treatment of non-atypical endometrial hyperplasia in perimenopausal women: a randomized controlled trial. J Gynecol Oncol, 24, 128-4.

Heller DS, Mosquera C, Goldsmith LT, Cracchiolo B (2011). Body mass index of patients with endometrial hyperplasia: comparison to patients with proliferative endometrium and abnormal bleeding. $J$ Reprod Med, 56, 110-2.

Kaya S, Kaya B, Keskin HL, Tetik BK, Yavuz FA(2019). Is there any relationship between benign endometrial pathologies and metabolic status?. J Obstet Gynaecol, 39, 176-3.

Ko EM, Sullivan S, Rambally B, et al (2016). Metformin for the treatment of endometrial hyperplasia. JClin Oncol, 34, 5592.

Korkmaz V, Özkaya E, Küçüközkan T, et al (2013). Medroxyprogesterone acetate plus metformin to prevent persistent endometrial hyperplasia. Gynecol Obstet Reprod Med, 19, 96-9.

Kurman RJ, Kaminski PF, Norris HJ (1985). The behavior of endometrial hyperplasia. A long-term study of "untreated" hyperplasia in 170 patients. Cancer, 56, 403-2.

Matthews DR, Hosker JP, Rudenski AS, et al (1985). Homeostasis model assessment: insulin resistance and beta-cell function from fasting plasma glucose and insulin concentrations in man. Diabetologia, 28, 412-9.

Misra A, Chowbey P, Makkar BM, et al (2009). Consensus statement for diagnosis of obesity, abdominal obesity and the metabolic syndrome for Asian Indians and recommendations for physical activity, medical and surgical management. J Assoc Physicians India, 57, 163-0.

Navaratnarajah R, Pillay OC, Hardiman P (2008). Polycystic ovary syndrome and endometrial cancer. Semin Reprod Med, 26, 62-1.

Royal College of Obstetricians and Gynaecologists (2016). Optimal management of endometrial hyperplasia. Green-Top Guideline No. 67 RCOG/BSGE, 67, pp 1-31. 
Sayyah-Melli M, Pourazad S, Gharebaghi PM, et al (2018). The comparative effect of combination of metformin and megestrol acetate with megestrol acetate alone on endometrial growth disorders. Int $J$ Womens Health Reprod Sci, 6, 211-5.

Session DR, Kalli KR, Tummon IS, Damario MA, Dumesic DA (2003). Treatment of atypical endometrial hyperplasia with an insulin-sensitizing agent. Gynecol Endocrinol, 17, 405-7.

Shan W, Wang C, Zhang Z, et al (2014). Conservative therapy with metformin plus megestrol acetate for endometrial atypical hyperplasia. $J$ Gynecol Oncol, 25, 214-0.

Sharifzadeh F, Aminimoghaddam S, Kashanian M, Fazaeli M, Sheikhansari N (2017). A comparison between the effects of metformin and megestrol on simple endometrial hyperplasia. Gynecol Endocrinol, 33, 152-5.

Sinha DP, Ahmed S, Baneerjee AK, Das M, Hassan H (2009). Significance of an index of insulin resistance in non-diabetic patients with impaired fasting glucose with acute myocardial infarction and its correlation to short term outcome. Indian Heart J, 61, 40-3.

Tabrizi AD, Melli MS, Foroughi M, Ghojazadeh M, Bidadi S (2014). Antiproliferative effect of Metformin on the Endometrium - a Clinical Trial. Asian Pac J Cancer Prev, 15, 10067-0.

Tan BK, Adya R, Chen J, et al (2011). Metformin treatment exerts antiinvasive and antimetastatic effects in human endometrial carcinoma cells. J Clin Endocrinol Metab, 96, 808-6.

Xie Y, Wang Y, Yu L, et al (2011). Metformin promotes progesterone receptor expression via inhibition of mammalian target of rapamycin (mTOR) in endometrial cancer cells. J Steroid Biochem Mol Biol, 126, 113-0.

Zhang Q, Celestino J, Schmandt R, et al (2013). Chemopreventive effects of metformin on obesity-associated endometrial proliferation. Am J Obstet Gynecol, 209, e1-2.

\section{cc) (i) (8)}

This work is licensed under a Creative Commons AttributionNon Commercial 4.0 International License. 